\title{
Reproducibility and relative validity of a FFQ to estimate the intake of fatty acids
}

\author{
Jaike Praagman ${ }^{1}$, Anda P. J. Adolphs ${ }^{1}$, Caroline T. M. van Rossum ${ }^{2}$, Ivonne Sluijs ${ }^{1}$, \\ Yvonne T. van der Schouw ${ }^{1 *}$ and Joline W. J. Beulens ${ }^{1,3}$ \\ ${ }^{1}$ Julius Center for Health Sciences and Primary Care, University Medical Center Utrecht, Stratenum 6.131, PO Box 85500, \\ 3508 GA Utrecht, The Netherlands \\ ${ }^{2}$ National Institute for Public Health Environment (RIVM), PO Box 1, 3720 BA Bilthoven, The Netherlands \\ ${ }^{3}$ Department of Epidemiology \& Biostatistics, EMGO + Institute of Health and Care Research, VU University Medical Center, \\ PO Box 7057, 1007 MB Amsterdam, The Netherlands
}

(Submitted 13 October 2015 - Final revision received 8 February 2016 - Accepted 8 March 2016 - First published online 15 April 2016)

\begin{abstract}
We investigated the validity and reproducibility of the FFQ used in the Dutch European Investigation of Cancer and Nutrition cohort, in order to rank subjects according to intakes of fatty acid classes and individual fatty acids. In total, 121 men and women (23-72 years) filled out three FFQ at 6-month intervals between 1991 and 1992. As a reference method, they filled out twelve monthly 24-h dietary recalls (24HDR) during the same year. Intra-class correlation coefficients for the FFQ showed moderate to good reproducibility across all fatty acids (classes and individual) in men (0.56-0.81) and women (0.57-0.83). In men, Spearman's correlation coefficients $\left(r_{\mathrm{s}}\right)$ for the FFQ compared with the 24HDR indicated moderate to good relative validity $\left(r_{\mathrm{s}}=0.45-0 \cdot 71\right)$ for all fatty acids, except for arachidonic acid and marine PUFA $\left(r_{\mathrm{s}}<0 \cdot 40\right)$. In women, relative validity was moderate to good for MUFA and trans-fatty acids (TFA) and the majority of SFA $\left(r_{\mathrm{s}}=0 \cdot 40-0 \cdot 66\right)$, was fair for the short-chain SFA and lauric acid $\left(r_{\mathrm{s}}=0.30-0.33\right)$ and was fair to moderate for PUFA $\left(r_{\mathrm{s}}=0.22-0 \cdot 47\right)$. Bland-Altman plots showed good agreement between the FFQ and $24 \mathrm{HDR}$, and proportional bias for fatty acids with very low intakes. In conclusion, the FFQ showed good reproducibility for subject ranking based on intakes of fatty acids (classes and individual). The relative validity measures indicated that the FFQ is an adequate tool to rank subjects according to intakes of high-abundant fatty acids, but less for low-abundant fatty acids.
\end{abstract}

\section{Key words: Reproducibility: Relative validity: FFQ: 24-h dietary recalls: Fatty acids}

The FFQ is a frequently used tool to measure dietary intakes in epidemiological studies on diet and disease. A self-administered semi-quantitative FFQ was used to measure the habitual consumption of foods and nutrients in the Dutch cohorts of the European Prospective Investigation into Cancer and Nutrition $(\mathrm{EPIC}-\mathrm{NL})^{(1)}$.

In 1991, before the start of the EPIC-NL study, the FFQ was validated against twelve 24-h dietary recalls (24HDR) to study its ability to rank subjects according to several foods ${ }^{(2)}$ and nutrients ${ }^{(3)}$, including total fat. However, up to today, this FFQ has not been validated for classes of fatty acids and individual fatty acids, although over time it has become evident that effects of dietary fats on (cardiovascular) health may differ across classes $^{(4)}$, and potentially even across individual fatty acids within these classes ${ }^{(5,6)}$. For the purpose of studying disease risks in relation to individual fatty acids in the EPIC-NL cohort, it is essential to assess the ability of its FFQ to capture their intake.

Several other FFQ were validated against $24 \mathrm{HDR}$ or food records for their ability to rank subjects according to several, but not all, individual fatty acids. The majority was focused on individual PUFA ${ }^{(7-16)}$ and oleic acid $(18: 1 n-9)^{(7-9,11-16)}$, and the validity varied from fair (correlation coefficients $(r)$ between 0.20 and 0.40 ) up to good ( $r$ between 0.60 and 0.80 ). Concerning individual SFA, studies focused on validating the medium- and long-chained SFA only ${ }^{(7,9,11,12,15,16)}$, of which only two ${ }^{(12,15)}$ reported on the validity of pentadecylic $(15: 0)$ and margaric (17:0) $\operatorname{acid}^{(15)}$, or capric (10:0) and lauric (12:0) $\operatorname{acid}^{(12)}$. All studies reported moderate to good relative validity $^{(7,11,12,15,16)}$, except for one, which observed fair-to-moderate validity $^{(9)}$. The relative validity for trans-fatty acid (TFA) intake was studied less often than the other fatty acid classes ${ }^{(8,11,17)}$, and ranged from poor ${ }^{(11)}$ to $\operatorname{good}^{(17)}$.

Other validity studies were carried out in different, nonDutch, populations with different dietary patterns. As the validity of an FFQ is specific to the study population and FFQ, we cannot translate the validity of other FFQ to the EPIC-NL FFQ. Therefore, in the present study, the reproducibility and relative validity of the FFQ, used in the EPIC-NL study, for

Abbreviations: 24HDR, 24-h dietary recall; AA, arachidonic acid; EPIC-NL, European Prospective Investigation into Cancer and Nutrition-The Netherlands; $\kappa_{w}$, weighted $\kappa$ coefficient; LA, linoleic acid; $r_{\mathrm{s}}$, Spearman's rank correlation coefficient; TFA, trans-fatty acid.

* Corresponding author: Y. T. van der Schouw, fax +31 88756 8099, email y.t.vanderschouw@umcutrecht.nl 
measuring fatty acid classes and individual SFA, including short- and medium-chain SFA, TFA, MUFA and PUFA, were investigated.

\section{Methods \\ Study population and data collection}

Description of the study population as well as the collection and processing of the data have been described in detail elsewhere ${ }^{(2)}$. In short, the validation study was carried out before the actual enrolment of the EPIC-NL cohort members, and started in 1991. A total of 960 healthy Dutch men and women from two ongoing projects in four towns were invited to participate in the study by postal mail. These subjects were representative of the EPIC-NL cohort members. Of the 240 (25\%) subjects who responded positively, 134 subjects were selected, equally distributed across the four towns, between both sexes, and in 20-year age groups. A total of sixty-three men and fifty-eight women, aged 23-72 years, completed the study. The results presented in this article apply to those 121 subjects. Data were collected over a period of 13 months, starting in October 1991. To assess the reproducibility, the FFQ was administered three times: in months 1, 7 and 13. During the same period, twelve $24 \mathrm{HDR}$ were administered once every month in order to assess relative validity.

The questionnaire was self-administered and contained questions on the habitual consumption frequency of seventynine main food items during the preceding year. Frequencies could be indicated in times per day, per week, per month or per year. For twenty-one foods, the questionnaire contained photographs of different portion sizes. For other foods, natural or household units were used to indicate portion size. The questionnaire contained additional questions about preparation methods and additions, and provided blank spaces for specification of brand names of margarines and cooking fats. Of the twelve $24 \mathrm{HDR}$, six were administered face-to-face and six by telephone without previous warning. For most subjects, the recall days included one Saturday and one Sunday, and all other weekdays were on average recalled twice. The recalls were performed by trained nutritionists and dietitians, and most subjects were interviewed by the same interviewer throughout the study period.

\section{Data processing and data analyses}

For each FFQ and 24HDR assessment, dietary intakes were calculated for each individual subject. The Dutch food composition table 1998 (digital update) was used to calculate the intake of individual fatty acids in grams per day. To correct for under-representation of weekend days, the weighted average of the $24 \mathrm{HDR}$ was calculated with a weight of one for weekdays and two for weekend days. The nutrient residual method was used to adjust fatty acid intakes for total energy intake $^{(18)}$. As the majority of fatty acids were not normally distributed (data not shown), intakes were expressed as medians with interquartile ranges. To compare the median intakes of the first FFQ (FFQ1) with FFQ2, FFQ3 and the 24HDR, the
Wilcoxon's signed-rank test was used. Intra-class correlation coefficients (ICC) were calculated with a two-way mixed model to obtain the reproducibility of the FFQ. To investigate the relative validity between FFQ1 and the weighted average of the twelve 24HDR, Spearman's rank correlation coefficients $\left(r_{\mathrm{s}}\right)$ were calculated. In addition, weighted $\kappa$ coefficients $\left(\kappa_{w}\right)$ were calculated to assess the degree of agreement in fatty acid intake quintiles according to the FFQ1 $v$, the 24HDR. The ICC, $r_{\mathrm{s}}$ and $\kappa_{w}$ were interpreted according to the following classification: poor $(\leq 0 \cdot 20)$, fair $(0 \cdot 21-0 \cdot 40)$, moderate $(0 \cdot 41-0 \cdot 60)$, good $(0 \cdot 61-0 \cdot 80)$ or excellent $(>0 \cdot 80)$. All the above-mentioned analyses were performed for both crude and energy-adjusted intakes. To assess absolute agreement between FFQ1 and the $24 \mathrm{HDR}$, we constructed Bland-Altman plots for energyadjusted fatty acid intakes only. In addition, we investigated whether potential bias was proportional to the levels of energyadjusted fatty acid intake using linear regression analysis.

Linear regression analysis showed that the relationship between fatty acid intakes as measured by the FFQ and as measured by the 24HDR differed significantly for men and women. Therefore, all analyses were stratified for sex. All the analyses were performed using SPSS version 20.0 (IBM) or SAS 9.2 (SAS Institute)

\section{Results}

A detailed description of the baseline characteristics of the study population can be found elsewhere ${ }^{(2)}$. In short, the mean age of men and women was $42 \cdot 6$ (SD 11.1) and $49 \cdot 0$ (SD 14.6) years, respectively. The average BMI was 25.5 (SD 2.9) kg/m² in men and $24.9(\mathrm{sD} 3.5) \mathrm{kg} / \mathrm{m}^{2}$ in women. Furthermore, $28 \%$ of both men and women attained higher vocational education or attended university.

The crude fatty acid intakes as measured by the FFQ and the 24HDR are shown in Tables 1 and 2 for men and women, respectively. Energy-adjusted intakes are presented in the online Supplementary Tables S1 and S2. In both men and women, FFQ1 overestimated the intakes of $16: 0$, TFA and total MUFA as well as individual MUFA and PUFA, as compared with the weighted average of the 24HDR. Similarly, median intakes measured with FFQ1 were significantly higher than those measured with FFQ3, except for PUFA.

Table 3 presents the ICC of the three repeated FFQ. ICC for crude fatty acids ranged from 0.56 to 0.75 in men and from 0.57 to 0.82 in women, indicating moderate to good reproducibility. The results were comparable for energy-adjusted fatty acids. The $r_{\mathrm{s}}$ for the fatty acids as measured by FFQ1 and the weighted average of the $24 \mathrm{HDR}$ are shown in Table 4 . In men, the relative validity was moderate to good for crude intakes of total and individual SFA and MUFA, TFA, linoleic acid (LA; $18: 2 n-6)$ and $\alpha$-linolenic acid (ALA; 18:3n-3), with $r_{\mathrm{s}}$ between 0.53 and 0.67. For energyadjusted intakes of these fatty acids, the coefficients were slightly different but still within the same range, except for stearic acid $(18: 0)\left(r_{\mathrm{s}}=0.47\right)$ and ALA $\left(r_{\mathrm{s}}=0.45\right)$, which were lower. Relative validity was lower for the low-abundant PUFA including arachidonic acid (AA; $20: 4 n-6)\left(r_{\mathrm{s}}=0.42\right)$ and the marine $n$-3 PUFA EPA $(20: 5 n-3)$ and DHA $(22: 6 n-3)\left(r_{s}<0 \cdot 40\right)$. Energy adjustment did not materially change these coefficients. 
Table 1. Fatty acid intakes $(\mathrm{g} / \mathrm{d})$ for the three measurements of the FFQ and the weighted average of the 24-h dietary recalls (24HDR) in sixty-three men (Medians and interquartile ranges (IQR))

\begin{tabular}{|c|c|c|c|c|c|c|c|c|}
\hline & \multicolumn{2}{|c|}{ FFQ1 } & \multicolumn{2}{|c|}{ FFQ2 } & \multicolumn{2}{|c|}{ FFQ3 } & \multicolumn{2}{|c|}{ 24HDR } \\
\hline & Median & IQR & Median & IQR & Median & IQR & Median & IQR \\
\hline \multicolumn{9}{|l|}{ SFA } \\
\hline Total & $42 \cdot 6$ & $32 \cdot 7-54.5$ & $40 \cdot 8^{\star}$ & $31 \cdot 3-49 \cdot 8$ & $39 \cdot 2^{\star \star}$ & $29 \cdot 4-47.5$ & $42 \cdot 3^{\star}$ & $31 \cdot 2-49 \cdot 2$ \\
\hline Butyric acid $(4: 0)$ & 0.54 & $0.33-0.89$ & $0.43^{\star \star \star}$ & $0 \cdot 27-0.70$ & $0.46^{\star *}$ & $0.31-0.68$ & 0.56 & $0.37-0.76$ \\
\hline Caproic acid $(6: 0)$ & 0.40 & $0.24-0.62$ & $0.31^{\star \star \star}$ & $0.19-0.50$ & $0.33^{\star *}$ & $0.22-0.49$ & 0.39 & $0.27-0.56$ \\
\hline Caprylic acid $(8: 0)$ & 0.30 & $0.20-0.40$ & $0.23^{\star \star \star}$ & $0.15-0.38$ & $0.23^{\star \star}$ & $0.16-0.35$ & 0.28 & $0.20-0.37$ \\
\hline Capric acid $(10: 0)$ & 0.58 & $0.35-0.75$ & $0.47^{\star \star \star}$ & $0.31-0.66$ & $0.46^{\star \star}$ & $0.32-0.72$ & $0.50^{\star \star}$ & $0.35-0.65$ \\
\hline Lauric acid (12:0) & 2.05 & $1 \cdot 32-2 \cdot 71$ & $1.68^{\star \star}$ & $1 \cdot 12-2 \cdot 44$ & $1.57^{\star *}$ & $1.03-2 \cdot 14$ & 1.69 & $1.26-2.36$ \\
\hline Myristic acid $(14: 0)$ & 4.4 & $3.1-5.5$ & $3.9^{\star \star}$ & $2 \cdot 5-5 \cdot 1$ & $3.9^{\star}$ & $2.5-4.7$ & 4.0 & $2 \cdot 8-5 \cdot 1$ \\
\hline Pentadecylic acid $(15: 0)$ & 0.56 & $0.41-0.73$ & $0.48^{\star \star *}$ & $0.33-0.65$ & $0.50^{\star \star}$ & $0.34-0.64$ & 0.54 & $0.38-0.71$ \\
\hline Palmitic acid $(16: 0)$ & $20 \cdot 1$ & $15 \cdot 7-26 \cdot 1$ & $19 \cdot 0^{\star \star}$ & $14.5-22.9$ & $18 \cdot 9^{\star \star \star}$ & $14.4-21.5$ & $19 \cdot 5^{\star \star}$ & $14 \cdot 1-22 \cdot 8$ \\
\hline Margaric acid $(17: 0)$ & 0.44 & $0.31-0.53$ & $0.40^{\star \star *}$ & $0.28-0.46$ & $0.39^{\star \star}$ & $0.28-0.48$ & 0.39 & $0.31-0.5$ \\
\hline Stearic acid $(18: 0)$ & 9.4 & $7 \cdot 5-12 \cdot 3$ & $9 \cdot 1^{\star}$ & $7 \cdot 1-11 \cdot 2$ & $8 \cdot 6^{\star \star}$ & $6 \cdot 8-10 \cdot 6$ & $9 \cdot 4$ & $7 \cdot 2-11 \cdot 4$ \\
\hline \multicolumn{9}{|l|}{ MUFA } \\
\hline Total & $40 \cdot 5$ & $31 \cdot 9-51 \cdot 7$ & 38.6 & $30 \cdot 6-49 \cdot 7$ & $36 \cdot 8^{\star}$ & $29 \cdot 4-45 \cdot 2$ & $37 \cdot 2^{\star \star}$ & $29 \cdot 0-45 \cdot 4$ \\
\hline Oleic acid $(18: 1 n-9)$ & 19.9 & $14 \cdot 6-26 \cdot 7$ & 19.5 & $13 \cdot 7-25 \cdot 2$ & $18 \cdot 8^{\star \star}$ & $14 \cdot 2-24 \cdot 2$ & $20 \cdot 0$ & $15 \cdot 4-26 \cdot 7$ \\
\hline \multicolumn{9}{|l|}{ TFA } \\
\hline Total & $4 \cdot 2$ & $3 \cdot 1-6 \cdot 1$ & $4 \cdot 0^{*}$ & $3 \cdot 0-5 \cdot 1$ & $3 \cdot 8^{\star *}$ & $2 \cdot 7-5 \cdot 2$ & $3 \cdot 8^{\star}$ & $2 \cdot 7-5 \cdot 2$ \\
\hline \multicolumn{9}{|l|}{ PUFA } \\
\hline Total & $23 \cdot 1$ & $17 \cdot 6-31 \cdot 0$ & $23 \cdot 2$ & $18 \cdot 8-29 \cdot 9$ & $22 \cdot 2$ & $16 \cdot 7-28 \cdot 2$ & $18 \cdot 3^{\star \star \star}$ & $14 \cdot 4-23 \cdot 7$ \\
\hline \multicolumn{9}{|l|}{$n-6$} \\
\hline Total & $16 \cdot 9$ & $12 \cdot 4-22 \cdot 3$ & $17 \cdot 7$ & $12 \cdot 9-21 \cdot 3$ & $15 \cdot 9$ & $12 \cdot 7-20 \cdot 5$ & $12 \cdot 7^{\star \star \star}$ & $9 \cdot 1-15 \cdot 3$ \\
\hline Linoleic acid $(18: 2 n-6)$ & $16 \cdot 7$ & $12 \cdot 4-22 \cdot 2$ & $17 \cdot 6$ & $12 \cdot 8-20 \cdot 9$ & $15 \cdot 8$ & $12 \cdot 6-20 \cdot 3$ & $12 \cdot 5^{\star \star \star}$ & $8 \cdot 9-15 \cdot 1$ \\
\hline Arachidonic acid $(20: 4 n-6)$ & 0.02 & $0.02-0.04$ & 0.02 & $0.02-0.04$ & $0.02^{*}$ & $0.02-0.03$ & $0.03^{* *}$ & $0.02-0.05$ \\
\hline \multicolumn{9}{|l|}{$n-3$} \\
\hline Total & 1.58 & $1 \cdot 24-2 \cdot 11$ & 1.56 & $1 \cdot 17-2 \cdot 01$ & $1.52^{*}$ & $1.08-1.93$ & $1.47^{\star}$ & $1.00-1.94$ \\
\hline$a$-Linolenic acid $(18: 3 n-3)$ & 1.44 & $1.09-1.87$ & 1.44 & $1.02-1.86$ & $1 \cdot 36^{\star}$ & $0.94-1.72$ & $1 \cdot 24^{\star \star}$ & $0.88-1.67$ \\
\hline $\operatorname{EPA}(20: 5 n-3)$ & 0.03 & $0.01-0.05$ & 0.02 & $0.01-0.05$ & 0.03 & $0.01-0.05$ & 0.02 & $0.00-0.12$ \\
\hline $\mathrm{DHA}(22: 6 n-3)$ & 0.07 & $0.04-0.13$ & $0.06^{\star}$ & $0.04-0.12$ & 0.06 & $0.04-0.12$ & 0.05 & $0.02-0.17$ \\
\hline
\end{tabular}

TFA, trans-fatty acid.

${ }^{\star} P<0.05,{ }^{\star \star} P<0.005,{ }^{\star \star \star} P<0.0001$ for significance of difference in median intake compared with FFQ1 as tested with the Wilcoxon's signed-rank test.

Table 2. Fatty acid intakes ( $\mathrm{g} / \mathrm{d})$ for the three measurements of the FFQ and the weighted average of the 24-h dietary recalls (24HDR) in fifty-eight women (Medians and interquartile ranges (IQR))

\begin{tabular}{|c|c|c|c|c|c|c|c|c|}
\hline & \multicolumn{2}{|c|}{ FFQ1 } & \multicolumn{2}{|c|}{ FFQ2 } & \multicolumn{2}{|c|}{ FFQ3 } & \multicolumn{2}{|c|}{ 24HDR } \\
\hline & Median & IQR & Median & IQR & Median & IQR & Median & IQR \\
\hline \multicolumn{9}{|l|}{ SFA } \\
\hline Total & 30.9 & $24 \cdot 5-37 \cdot 8$ & 28.7 & $23 \cdot 7-35 \cdot 2$ & $26 \cdot 7^{\star \star}$ & $22 \cdot 3-34.9$ & 29.5 & $25 \cdot 7-33 \cdot 5$ \\
\hline Butyric acid $(4: 0)$ & 0.43 & $0.32-0.57$ & 0.44 & $0.31-0.57$ & $0.38^{\star \star}$ & $0.24-0.52$ & 0.45 & $0.35-0.59$ \\
\hline Caproic acid $(6: 0)$ & 0.31 & $0.23-0.40$ & 0.31 & $0.22-0.40$ & $0.27^{\star \star}$ & $0.17-0.37$ & 0.32 & $0.25-0.41$ \\
\hline Caprylic acid (8:0) & 0.23 & $0.17-0.28$ & 0.23 & $0.17-0.29$ & $0.20^{\star \star}$ & $0.14-0.24$ & 0.21 & $0.17-0.27$ \\
\hline Capric acid $(10: 0)$ & 0.41 & $0.31-0.52$ & 0.40 & $0.32-0.53$ & $0.37^{\star \star}$ & $0.31-0.47$ & 0.39 & $0.32-0.51$ \\
\hline Lauric acid $(12: 0)$ & 1.37 & $1.06-1.85$ & 1.41 & $0.99-1.86$ & $1.25^{\star}$ & $0.99-1.55$ & 1.38 & $1.08-1.7$ \\
\hline Myristic acid (14:0) & 3.0 & $2.4-3.9$ & 2.9 & $2 \cdot 4-3 \cdot 6$ & $2 \cdot 8^{\star \star \star}$ & $2 \cdot 1-3.5$ & 3.1 & $2 \cdot 4-3 \cdot 8$ \\
\hline Pentadecylic acid (15:0) & 0.41 & $0.33-0.55$ & 0.41 & $0.32-0.53$ & $0.40^{\star \star}$ & $0.26-0.46$ & 0.41 & $0.34-0.51$ \\
\hline Palmitic acid $(16: 0)$ & $14 \cdot 1$ & $10 \cdot 9-17.5$ & $13 \cdot 2$ & $10 \cdot 8-15 \cdot 9$ & $12 \cdot 0^{\star \star}$ & $10 \cdot 0-15 \cdot 6$ & $13 \cdot 1^{*}$ & $10 \cdot 9-15 \cdot 8$ \\
\hline Margaric acid $(17: 0)$ & 0.30 & $0.24-0.37$ & 0.29 & $0.24-0.35$ & $0.26^{\star \star}$ & $0.21-0.33$ & 0.29 & $0.24-0.36$ \\
\hline Stearic acid $(18: 0)$ & 6.5 & $5 \cdot 3-8.5$ & $6 \cdot 4$ & $5 \cdot 2-7.9$ & $5 \cdot 8^{\star \star}$ & $5 \cdot 1-7 \cdot 7$ & $6 \cdot 3$ & $5 \cdot 3-7 \cdot 5$ \\
\hline \multicolumn{9}{|l|}{ MUFA } \\
\hline Total & $28 \cdot 0$ & $22 \cdot 3-33 \cdot 7$ & $26 \cdot 4$ & $20 \cdot 8-23 \cdot 2$ & $25 \cdot 4^{\star \star}$ & $20 \cdot 6-31 \cdot 0$ & $24.5^{\star \star \star}$ & $20 \cdot 5-30 \cdot 0$ \\
\hline Oleic acid $(18: 1 n-9)$ & 14.0 & $11 \cdot 2-18 \cdot 1$ & $12 \cdot 1$ & $10 \cdot 7-17 \cdot 2$ & $12 \cdot 1^{\star \star}$ & $10 \cdot 0-16 \cdot 4$ & $12 \cdot 8^{\star}$ & $10 \cdot 2-15 \cdot 3$ \\
\hline \multicolumn{9}{|l|}{ TFA } \\
\hline Total & $2 \cdot 8$ & $2 \cdot 1-3 \cdot 7$ & 3.0 & $2 \cdot 0-3 \cdot 6$ & $2 \cdot 6^{\star \star}$ & $1 \cdot 8-3 \cdot 3$ & $2 \cdot 6$ & $2 \cdot 1-3 \cdot 3$ \\
\hline \multicolumn{9}{|l|}{ PUFA } \\
\hline Total & $17 \cdot 0$ & $12 \cdot 6-20 \cdot 5$ & $16 \cdot 6$ & $12 \cdot 2-20 \cdot 9$ & $16 \cdot 4$ & $11 \cdot 8-19 \cdot 8$ & $11 \cdot 1^{\star \star \star}$ & $9 \cdot 2-15 \cdot 7$ \\
\hline \multicolumn{9}{|l|}{$n-6$} \\
\hline Total & $12 \cdot 2$ & $9 \cdot 5-16 \cdot 2$ & 11.6 & $8 \cdot 6-15 \cdot 6$ & 11.4 & $8.5-13.9$ & $7 \cdot 2^{\star \star \star}$ & $5 \cdot 7-9 \cdot 3$ \\
\hline Linoleic acid $(18: 2 n-6)$ & $12 \cdot 1$ & $9 \cdot 3-16 \cdot 0$ & 11.5 & $8 \cdot 5-15 \cdot 4$ & $11 \cdot 2$ & $8.5-13.7$ & $7 \cdot 0^{\star \star}$ & $5 \cdot 6-9 \cdot 2$ \\
\hline Arachidonic acid $(20: 4 n-6)$ & 0.02 & $0.02-0.03$ & 0.02 & $0.01-0.03$ & 0.02 & $0.01-0.03$ & $0.03^{\star \star}$ & $0.02-0.04$ \\
\hline \multicolumn{9}{|l|}{$n-3$} \\
\hline Total & 1.26 & $0.94-1.42$ & 1.14 & $0.87-1.73$ & 1.09 & $0.86-1.40$ & $0.95^{\star \star}$ & $0.71-1.32$ \\
\hline$a$-Linolenic acid $(18: 3 n-3)$ & $1 \cdot 10$ & $0.82-1.30$ & 1.01 & $0.80-1.37$ & 0.95 & $0.72-1.23$ & $0.82^{\star *}$ & $0.60-1.08$ \\
\hline $\operatorname{EPA}(20: 5 n-3)$ & 0.03 & $0.01-0.05$ & 0.03 & $0.01-0.04$ & 0.03 & $0.01-0.04$ & 0.02 & $0.00-0.04$ \\
\hline $\mathrm{DHA}(22: 6 n-3)$ & 0.07 & $0.02-0.11$ & 0.07 & $0.03-0.11$ & 0.07 & $0.04-0.10$ & $0.04^{\star \star}$ & $0.02-0.07$ \\
\hline
\end{tabular}

TFA, trans-fatty acid.

${ }^{\star} P<0.05,{ }^{\star \star} P<0.005,{ }^{* \star *} P<0.0001$ for significance of difference in median intake compared with FFQ1 as tested with the Wilcoxon's signed-rank test. 
Table 3. Associations of three repeated FFQ, used for dietary measurement in the Dutch European Prospective Investigation into Cancer and Nutrition cohort (Intra-class correlation coefficients (ICC) and 95\% confidence intervals)

\begin{tabular}{|c|c|c|c|c|c|c|c|c|}
\hline & \multicolumn{4}{|c|}{ Men (n 63) } & \multicolumn{4}{|c|}{ Women (n 58) } \\
\hline & \multicolumn{2}{|c|}{ Crude } & \multicolumn{2}{|c|}{ Adjusted* } & \multicolumn{2}{|c|}{ Crude } & \multicolumn{2}{|c|}{ Adjusted } \\
\hline & ICC & $95 \% \mathrm{Cl}$ & ICC & $95 \% \mathrm{Cl}$ & ICC & $95 \% \mathrm{Cl}$ & ICC & $95 \% \mathrm{Cl}$ \\
\hline \multicolumn{9}{|l|}{ SFA } \\
\hline Total & 0.73 & $0.62,0.82$ & 0.67 & $0.51,0.78$ & 0.79 & $0.69,0.87$ & 0.69 & $0.45,0.82$ \\
\hline $4: 0$ & 0.70 & $0.57,0.79$ & 0.68 & $0.56,0.78$ & 0.77 & $0.66,0.85$ & 0.68 & $0.55,0.79$ \\
\hline $6: 0$ & 0.69 & $0.56,0.79$ & 0.68 & $0.56,0.78$ & 0.76 & $0.66,0.85$ & 0.68 & $0.54,0.79$ \\
\hline $8: 0$ & 0.59 & $0.46,0.71$ & 0.67 & $0.55,0.78$ & 0.66 & $0.53,0.77$ & 0.66 & $0.53,0.77$ \\
\hline $10: 0$ & 0.67 & $0.54,0.77$ & 0.72 & $0.60,0.81$ & 0.80 & $0.71,0.88$ & 0.75 & $0.62,0.84$ \\
\hline $12: 0$ & 0.58 & $0.45,0.70$ & 0.66 & $0.54,0.76$ & 0.68 & $0.56,0.79$ & 0.66 & $0.53,0.77$ \\
\hline $14: 0$ & 0.67 & $0.54,0.77$ & 0.68 & $0.55,0.78$ & 0.82 & $0.73,0.89$ & 0.74 & $0.58,0.84$ \\
\hline $15: 0$ & 0.69 & $0.56,0.79$ & 0.69 & $0.56,0.79$ & 0.83 & $0.75,0.90$ & 0.74 & $0.60,0.84$ \\
\hline $16: 0$ & 0.71 & $0.59,0.80$ & 0.64 & $0.47,0.77$ & 0.79 & $0.69,0.69$ & 0.70 & $0.46,0.83$ \\
\hline $17: 0$ & 0.67 & $0.54,0.77$ & 0.65 & $0.50,0.76$ & 0.82 & $0.73,0.89$ & 0.69 & $0.51,0.81$ \\
\hline $18: 0$ & 0.67 & $0.55,0.78$ & 0.60 & $0.44,0.72$ & 0.79 & $0.69,0.87$ & 0.74 & $0.56,0.85$ \\
\hline \multicolumn{9}{|l|}{ MUFA } \\
\hline Total & 0.75 & $0.64,0.83$ & 0.67 & $0.52,0.78$ & 0.75 & $0.64,0.83$ & 0.73 & $0.56,0.83$ \\
\hline $18: 1 n-9$ & 0.73 & $0.62,0.81$ & 0.71 & $0.57,0.81$ & 0.71 & $0.58,0.80$ & 0.67 & $0.47,0.79$ \\
\hline \multicolumn{9}{|l|}{ TFA } \\
\hline Total & 0.67 & $0.55,0.77$ & 0.65 & $0.52,0.75$ & 0.79 & $0.70,0.86$ & 0.79 & $0.69,0.86$ \\
\hline PUFA & & & & & & & & \\
\hline Total & 0.70 & $0.59,0.79$ & 0.65 & $0.52,0.75$ & 0.73 & $0.61,0.82$ & 0.59 & $0.45,0.72$ \\
\hline \multicolumn{9}{|l|}{$n-6$} \\
\hline Total & 0.56 & $0.42,0.69$ & 0.59 & $0.46,0.71$ & 0.64 & $0.51,0.75$ & 0.61 & $0.47,0.73$ \\
\hline $18: 2 n-6$ & 0.56 & $0.42,0.69$ & 0.60 & $0.46,0.71$ & 0.64 & $0.51,0.75$ & 0.61 & $0.47,0.73$ \\
\hline $20: 4 n-6$ & 0.81 & $0.72,0.87$ & 0.77 & $0.68,0.85$ & 0.69 & $0.57,0.79$ & 0.71 & $0.59,0.80$ \\
\hline \multicolumn{9}{|l|}{$n-3$} \\
\hline Total & 0.67 & $0.55,0.77$ & 0.67 & $0.55,0.77$ & 0.62 & $0.49,0.74$ & 0.60 & $0.46,0.72$ \\
\hline $18: 3 n-3$ & 0.68 & $0.56,0.78$ & 0.68 & $0.55,0.78$ & 0.63 & $0.49,0.74$ & 0.58 & $0.43,0.71$ \\
\hline $20: 5 n-3$ & 0.65 & $0.53,0.76$ & 0.61 & $0.47,0.72$ & 0.59 & $0.44,0.71$ & 0.60 & $0.46,0.72$ \\
\hline $22: 6 n-3$ & 0.64 & $0.51,0.75$ & 0.63 & $0.50,0.74$ & 0.60 & $0.46,0.72$ & 0.62 & $0.48,0.74$ \\
\hline
\end{tabular}

TFA, trans-fatty acid

* All fatty acid intakes were adjusted for total energy intake using the residual method ${ }^{(18)}$.

In women, the $r_{\mathrm{s}}$ between FFQ1 and the 24HDR showed moderate to good relative validity for all SFA $\left(r_{\mathrm{s}}\right.$ from 0.51 to $0.62)$, except for caprylic acid $(8: 0)\left(r_{s}=0.35\right)$ and lauric acid $\left(r_{\mathrm{s}}=0.33\right)$, for which validity was fair. Energy adjustment lowered most correlations ( $r_{\mathrm{s}}$ from 0.30 to $0 \cdot 50$ ), except for palmitic acid $(16: 0)\left(r_{\mathrm{s}}=0.62\right)$ and capric acid $\left(r_{\mathrm{s}}=0.66\right)$. For MUFA and TFA, the $r_{\mathrm{s}}$ were, respectively, 0.63 and 0.56 for crude intakes and 0.58 and 0.49 for energy-adjusted intakes. For individual PUFA, the $r_{\mathrm{s}}$ varied from 0.33 to 0.44 for $n-6$ PUFA and from 0.28 to 0.36 for $n-3$ PUFA. The correlation coefficients for energy-adjusted PUFA intakes were higher for AA and EPA but lower for total PUFA, ALA and DHA.

Table 5 presents the $\kappa_{w}$ between FFQ1 and the 24HDR. In men, the agreement between FFQ1 and the 24HDR was fair for crude intake of lauric acid and moderate for the other individual SFA and total SFA ( $\kappa_{w}$ from 0.40 to 0.48 ). After energy adjustment, the agreement was fair for the short-chain SFA, caprylic acid, lauric acid and margaric acid $\left(\kappa_{w}\right.$ from $0 \cdot 34$ to 0.38 ), and moderate for all other SFA ( $\kappa_{w}$ from 0.44 to 0.52). Moderate agreement was observed for crude intakes of MUFA, TFA and all PUFA, except AA $\left(\kappa_{w}=0.31\right)$ and marine $n$-3 PUFA (median $\kappa_{w}=0 \cdot 21$ ), which were considered fair. In general, the $\kappa_{w}$ were slightly lower for energy-adjusted intakes of MUFA, TFA and PUFA. In women, $\kappa_{w}$ between FFQ1 and the 24HDR were $0.47,0.41,0.50$ and 0.43 for crude intakes of, respectively, total SFA, capric acid, palmitic acid and stearic acid (18:0). For the other SFA, $\kappa_{w}$ coefficients were lower, ranging from $0 \cdot 19$ to $0 \cdot 39$. For crude intakes of MUFA and TFA, $\kappa_{w}$ coefficients were 0.43 and 0.34 , respectively. $\kappa_{w}$ Coefficients for PUFA ranged from 0.17 (EPA) to 0.28 (total PUFA). Energy adjustment in general lowered the $\kappa_{w}$ coefficients for all fatty acids.

Bland-Altman plots showed systematic, non-proportional overestimation by FFQ1 as compared with the weighted average of the 24HDR of intakes of palmitic acid and TFA in both men and women (see online Supplementary Fig. S1-S44). In men, proportional bias was observed for butyric acid (4:0), caproic acid $(6: 0)$ and pentadecylic acid, indicating underestimation at lower intake levels and overestimation at higher intake levels. In addition, for PUFA and LA, the overestimation was positively proportional to the levels of intake. For $\mathrm{AA}$ and $n-3$ PUFA, the proportional bias was negative, demonstrating underestimation by the FFQ at higher levels of intake. In women, a slight overestimation was observed for most SFA, which was positively proportional for capric acid only. Intake of total PUFA was systematically overestimated, showing no proportional bias, whereas the overestimation of LA increased with increased levels of intake, and intakes of AA, EPA and DHA showed negatively proportional bias. 
Table 4. Associations between FFQ1 and the weighted average of 24-h dietary recalls (Spearman's rank correlation coefficients $\left(r_{\mathrm{s}}\right)$ and $95 \%$ confidence intervals)

\begin{tabular}{|c|c|c|c|c|c|c|c|c|}
\hline & \multicolumn{4}{|c|}{ Men ( $n$ 63) } & \multicolumn{4}{|c|}{ Women ( $n$ 58) } \\
\hline & \multicolumn{2}{|c|}{ Crude } & \multicolumn{2}{|c|}{ Adjusted ${ }^{*}$} & \multicolumn{2}{|c|}{ Crude } & \multicolumn{2}{|c|}{ Adjusted ${ }^{\star}$} \\
\hline & $r_{\mathrm{s}}$ & $95 \% \mathrm{Cl}$ & $r_{\mathrm{s}}$ & $95 \% \mathrm{Cl}$ & $r_{\mathrm{s}}$ & $95 \% \mathrm{Cl}$ & $r_{\mathrm{s}}$ & $95 \% \mathrm{Cl}$ \\
\hline \multicolumn{9}{|l|}{ SFA } \\
\hline Total & 0.65 & $0.47,0.77$ & 0.55 & $0.35,0.70$ & 0.64 & $0.46,0.77$ & 0.50 & $0.28,0.67$ \\
\hline $4: 0$ & 0.64 & $0.47,0.77$ & 0.61 & $0.42,0.74$ & 0.51 & $0.29,0.68$ & 0.30 & $0.04,0.52$ \\
\hline $6: 0$ & 0.64 & $0.47,0.77$ & 0.61 & $0.42,0.74$ & 0.51 & $0.29,0.68$ & 0.32 & $0.07,0.54$ \\
\hline $8: 0$ & 0.60 & $0.41,0.74$ & 0.59 & $0.41,0.73$ & 0.35 & $0.10,0.56$ & 0.43 & $0.19,0.62$ \\
\hline $10: 0$ & 0.65 & $0.49,0.78$ & 0.71 & $0.56,0.81$ & 0.63 & $0.45,0.76$ & 0.66 & $0.49,0.78$ \\
\hline $12: 0$ & 0.54 & $0.34,0.70$ & 0.53 & $0.33,0.69$ & 0.33 & $0.08,0.54$ & 0.33 & $0.08,0.54$ \\
\hline $14: 0$ & 0.60 & $0.42,0.74$ & 0.67 & $0.51,0.79$ & 0.59 & $0.39,0.73$ & 0.50 & $0.27,0.67$ \\
\hline $15: 0$ & 0.62 & $0.44,0.75$ & 0.66 & $0.50,0.78$ & 0.53 & $0.31,0.69$ & 0.42 & $0.18,0.61$ \\
\hline $16: 0$ & 0.63 & $0.45,0.76$ & 0.62 & $0.44,0.75$ & 0.65 & $0.47,0.78$ & 0.62 & $0.43,0.76$ \\
\hline $17: 0$ & 0.55 & $0.35,0.70$ & 0.54 & $0.34,0.70$ & 0.54 & $0.32,0.70$ & 0.40 & $0.15,0.59$ \\
\hline $18: 0$ & 0.62 & $0.44,0.75$ & 0.47 & $0.25,0.64$ & 0.64 & $0.45,0.77$ & 0.49 & $0.26,0.66$ \\
\hline \multicolumn{9}{|l|}{ MUFA } \\
\hline Total & 0.67 & $0.51,0.79$ & 0.66 & $0.49,0.78$ & 0.63 & $0.45,0.76$ & 0.58 & $0.38,0.73$ \\
\hline $18: 1 n-9$ & 0.66 & $0.49,0.78$ & 0.60 & $0.42,0.74$ & 0.48 & $0.25,0.65$ & 0.51 & $0.29,0.68$ \\
\hline \multicolumn{9}{|l|}{ TFA } \\
\hline Total & 0.63 & $0.46,0.76$ & 0.53 & $0.32,0.68$ & 0.56 & $0.36,0.72$ & 0.49 & $0.27,0.67$ \\
\hline \multicolumn{9}{|l|}{ PUFA } \\
\hline Total & 0.53 & $0.33,0.69$ & 0.52 & $0.31,0.68$ & 0.44 & $0.20,0.63$ & 0.22 & $-0.04,0.45$ \\
\hline$n-6$ & 0.55 & $0.36,0.71$ & 0.58 & $0.39,0.73$ & 0.41 & $0.17,0.60$ & 0.38 & $0.14,0.58$ \\
\hline $18: 2 n-6$ & 0.56 & $0.36,0.71$ & 0.58 & $0.39,0.73$ & 0.42 & $0.18,0.61$ & 0.38 & $0.14,0.58$ \\
\hline $20: 4 n-6$ & 0.42 & $0.20,0.61$ & 0.31 & $0.06,0.51$ & 0.33 & $0.08,0.54$ & 0.47 & $0.24,0.65$ \\
\hline$n-3$ & 0.57 & $0.37,0.72$ & 0.46 & $0.24,0.64$ & 0.35 & $0.10,0.55$ & 0.34 & $0.09,0.55$ \\
\hline $18: 3 n-3$ & 0.60 & $0.41,0.74$ & 0.45 & $0.23,0.63$ & 0.36 & $0.11,0.56$ & 0.23 & $-0.03,0.46$ \\
\hline $20: 5 n-3$ & 0.35 & $0.12,0.55$ & 0.36 & $0.12,0.56$ & 0.38 & $0.14,0.58$ & 0.40 & $0.16,0.60$ \\
\hline $22: 6 n-3$ & 0.30 & $0.06,0.51$ & 0.32 & $0.08,0.53$ & 0.34 & $0.09,0.55$ & 0.22 & $-0.04,0.45$ \\
\hline
\end{tabular}

TFA, trans-fatty acid.

* All fatty acid intakes were adjusted for total energy intake using the residual method ${ }^{(18)}$.

\section{Discussion}

The reproducibility of the FFQ, used in EPIC-NL, was moderate to good for all fatty acid classes and individual fatty acids in both men and women. In men, the relative validity of the FFQ was moderate to good for all fatty acids, but fair for the low-abundant long-chain PUFA. In women, moderate to good relative validity was observed for SFA that are highly abundant in the Dutch diet, as well as for TFA and MUFA. The relative validity of low-abundant SFA and PUFA was fair to moderate, with the lowest validity observed for the marine $n-3$ fatty acids. Compared with the weighted average of the $24 \mathrm{HDR}$, the FFQ generally overestimated fatty acid intake, and showed proportional bias for low-abundant fatty acids, particularly the short-chain SFA and the PUFA.

Strengths of this study include the size of the study population and the equal distribution of subject characteristics such as age and sex. Furthermore, we used data from twelve repeated 24HDR and the FFQ was administered three times at 6-month intervals. A limitation of the study is that the reference method we used, the $24 \mathrm{HDR}$, has correlated errors with the FFQ, such as the reliance on memory, socially desirable answering and use of the same food composition database for calculations of nutrient intakes. Such correlated errors can lead to artificially high correlations between the two methods ${ }^{(19)}$. A reference method that has no correlated errors to the FFQ is the biomarker. Fatty acid levels measured in, for instance, erythrocytes, plasma or adipose tissue can be used as biomarkers for dietary fatty acid intake, but only for the (largely) exogenously derived ones such as EPA, DHA, TFA, pentadecylic acid and margaric acid. Fatty acid biomarkers do not reflect dietary intakes of fatty acids that are largely endogenously derived, such as SFA and MUFA ${ }^{(20)}$. For the present study population, no biomarkers were available. A previous study in a subsample of the total EPIC cohort (which apart from EPIC-NL includes cohorts from nine other countries ${ }^{(21)}$ ) compared mean plasma phospholipid fatty acid profiles with mean intakes of food groups as measured by the country-specific FFQ, including the EPIC-NL FFQ ${ }^{(22)}$. In that study, exogenously derived fatty acids significantly correlated with those foods that are important contributors to their intake. To illustrate, plasma phospholipid measures of the sum of pentadecylic acid and margaric acid were correlated with dairy product intake as measured by the FFQ. Moreover, 18:1n-9t correlated with intakes of dairy foods and margarine, and DHA correlated with fatty fish intake. This indirectly suggests that the EPIC FFQ are well capable of measuring the intakes of these fatty acids. However, we should be careful with directly applying this to the EPIC-NL FFQ as the previous findings are based on combined study populations from different European countries with each having their own FFQ, and it does not compare estimates on the individual fatty acid level. Our study showed that the 
Table 5. Agreement between fatty acid intake quintiles of FFQ1 and the weighted average of 24-h dietary recalls (Weighted $k$ coefficients $\left(\kappa_{w}\right)$ and $95 \%$ confidence intervals)

\begin{tabular}{|c|c|c|c|c|c|c|c|c|}
\hline & \multicolumn{4}{|c|}{ Men } & \multicolumn{4}{|c|}{ Women } \\
\hline & \multicolumn{2}{|c|}{ Crude } & \multicolumn{2}{|c|}{ Adjusted* } & \multicolumn{2}{|c|}{ Crude } & \multicolumn{2}{|c|}{ Adjusted* } \\
\hline & $\kappa_{w}$ & $95 \% \mathrm{Cl}$ & $\kappa_{w}$ & $95 \% \mathrm{Cl}$ & $\kappa_{w}$ & $95 \% \mathrm{Cl}$ & $\kappa_{w}$ & $95 \% \mathrm{Cl}$ \\
\hline \multicolumn{9}{|l|}{ SFA } \\
\hline Total & 0.46 & $0.29,0.62$ & 0.34 & $0.17,0.50$ & 0.47 & $0.32,0.63$ & 0.36 & $0.19,0.54$ \\
\hline $4: 0$ & 0.44 & $0.29,0.58$ & 0.38 & $0.22,0.53$ & 0.34 & $0.17,0.52$ & 0.21 & $0.04,0.38$ \\
\hline $6: 0$ & 0.42 & $0.27,0.56$ & 0.38 & $0.22,0.53$ & 0.28 & $0.11,0.44$ & 0.21 & $0.05,0.37$ \\
\hline $8: 0$ & 0.42 & $0.27,0.56$ & 0.36 & $0.22,0.49$ & 0.19 & $0.01,0.37$ & 0.34 & $0.16,0.52$ \\
\hline $10: 0$ & 0.48 & $0.32,0.63$ & 0.48 & $0.35,0.60$ & 0.41 & $0.25,0.56$ & 0.43 & $0.27,0.59$ \\
\hline $12: 0$ & 0.34 & $0.19,0.48$ & 0.36 & $0.20,0.50$ & 0.19 & $0.01,0.37$ & 0.30 & $0.11,0.49$ \\
\hline $14: 0$ & 0.42 & $0.26,0.57$ & 0.52 & $0.37,0.66$ & 0.36 & $0.21,0.51$ & 0.32 & $0.15,0.49$ \\
\hline $15: 0$ & 0.42 & $0.26,0.57$ & 0.48 & $0.33,0.62$ & 0.34 & $0.18,0.50$ & 0.30 & $0.12,0.47$ \\
\hline $16: 0$ & 0.46 & $0.30,0.61$ & 0.44 & $0.28,0.59$ & 0.50 & $0.35,0.65$ & 0.43 & $0.28,0.58$ \\
\hline $17: 0$ & 0.40 & $0.24,0.56$ & 0.38 & $0.21,0.54$ & 0.39 & $0.23,0.55$ & 0.25 & $0.08,0.43$ \\
\hline $18: 0$ & 0.42 & $0.26,0.57$ & 0.27 & $0.11,0.44$ & 0.43 & $0.28,0.58$ & 0.36 & $0.19,0.54$ \\
\hline \multicolumn{9}{|l|}{ MUFA } \\
\hline Total & 0.50 & $0.35,0.64$ & 0.40 & $0.26,0.53$ & 0.43 & $0.28,0.58$ & 0.39 & $0.23,0.54$ \\
\hline $18: 1 n-9$ & 0.50 & $0.35,0.64$ & 0.48 & $0.33,0.62$ & 0.32 & $0.15,0.49$ & 0.34 & $0.18,0.50$ \\
\hline \multicolumn{9}{|l|}{ TFA } \\
\hline Total & 0.48 & $0.32,0.63$ & 0.36 & $0.19,0.52$ & 0.34 & $0.18,0.51$ & 0.32 & $0.15,0.49$ \\
\hline \multicolumn{9}{|l|}{ PUFA } \\
\hline Total & 0.40 & $0.23,0.56$ & 0.34 & $0.17,0.50$ & 0.28 & $0.10,0.46$ & 0.14 & $-0.04,0.33$ \\
\hline$n-6$ & 0.40 & $0.23,0.56$ & 0.42 & $0.26,0.57$ & 0.19 & $0.02,0.36$ & 0.21 & $0.03,0.39$ \\
\hline $18: 2 n-6$ & 0.40 & $0.23,0.56$ & 0.40 & $0.24,0.55$ & 0.19 & $0.02,0.35$ & 0.19 & $0.01,0.37$ \\
\hline $20: 4 n-6$ & 0.31 & $0.16,0.47$ & 0.13 & $-0.04,0.31$ & 0.21 & $0.03,0.39$ & 0.25 & $0.08,0.42$ \\
\hline$n-3$ & 0.40 & $0.24,0.55$ & 0.34 & $0.16,0.51$ & 0.21 & $0.03,0.39$ & 0.21 & $0.04,0.39$ \\
\hline $18: 3 n-3$ & 0.40 & $0.23,0.56$ & 0.31 & $0.14,0.49$ & 0.23 & $0.06,0.41$ & 0.10 & $-0.07,0.27$ \\
\hline $20: 5 n-3$ & 0.21 & $0.03,0.39$ & 0.27 & $0.10,0.45$ & 0.17 & $-0.00,0.34$ & 0.19 & $0.01,0.37$ \\
\hline $22: 6 n-3$ & 0.21 & $0.04,0.39$ & 0.17 & $-0.00,0.35$ & 0.19 & $0.01,0.36$ & 0.12 & $-0.07,0.31$ \\
\hline
\end{tabular}

TFA, trans-fatty acid.

* All fatty acid intakes were adjusted for total energy intake using the residual method ${ }^{(18)}$.

reproducibility of the FFQ for fatty acid intake assessment in general was good, with ICC ranging from 0.56 to 0.83 . These ICC are of the same magnitude as those presented in other studies that assessed the reproducibility of an FFQ for classes of fatty acids ${ }^{(23-26)}$ and a limited number of individual PUFA ${ }^{(25,26)}$. One study reported lower ICC ranging from 0.28 for total PUFA to 0.61 for $\mathrm{DHA}^{(27)}$.

We observed an overestimation of intake of the majority of fatty acids assessed by the first FFQ as compared with the third FFQ, which is in line with a previous reproducibility study on dietary fatty acid measurements ${ }^{(27)}$. The first FFQ also overestimated fatty acid intakes as compared with the $24 \mathrm{HDR}$, which was also observed in several previous validation studies ${ }^{(8-10,13)}$, although not in all $^{(15)}$. Overestimation is very common for questionnaires that cover more than 100 food items and pertain to a long time period ${ }^{(13)}$, such as the FFQ used in our study.

In general, the relative validity for subject ranking in our study was lower among women than among men. This is in line with the lower validity among women in a previous validation study of this FFQ for food groups that largely contribute to fatty acids intake, including cheese, nuts and seeds, and biscuits and pastries $^{(2)}$. Previously, it was shown that under-reporting more often applies to foods that are rich in fats ${ }^{(28)}$, and some studies $^{(29-32)}$, although not all ${ }^{(33-35)}$, showed that underreporters are more often women, which may explain the lower validity we observed.
Energy adjustment is often used in validation studies to cancel out correlated errors between the two measurement tools ${ }^{(19)}$. In the present study, energy adjustment of fatty acid intake did not improve the validity, and in many cases even lowered the validity. This is in contrast to what is expected based on a study that reported improvement in the validity of three different FFQ after energy adjustment ${ }^{(36)}$. It is unclear why energy adjustment caused lower relative validity in our study.

In general, the relative validity of the FFQ in the present study was moderate to good for intakes of individual SFA. Results from previous validation studies on SFA with chain lengths of ten carbon atoms and over that used $24 \mathrm{HDR}^{(9,15)}$ or (weighed) food records ${ }^{(7,11,12,16)}$ as their reference method were similar to ours. The ability to rank subjects according to intake of SFA that are less abundant in the diet, including short-chain SFA and odd-chain SFA, was less among women. To our knowledge, no previous studies have validated an FFQ against 24HDR or diet records for shorter-chain SFA. It is conceivable that because of the small between-subject and within-subject variation in intake of these SFA, overestimation by the FFQ as compared with the $24 \mathrm{HDR}$ will easily lead to changes in subject ranking, and thus to lower validity.

For measurement of individual PUFA, and in particular the marine $n$-3 PUFA, which are less abundant in the Dutch diet, the relative validity was low in our study, and considered fair. Previous validation studies showed varying results for the 
measurement of EPA and DHA. Some studies observed fair validity $(r<0 \cdot 40)^{(10,13,15)}$, similar to our study, whereas other studies report moderate $(0 \cdot 40 \leq r<0 \cdot 60)^{(7,8,12,16)}$ to good validity $(r \geq 0 \cdot 60)^{(14)}$. The lower validity in our study may be caused by the type of reference method used. Studies that showed the lowest validity all used $24 \mathrm{HDR}^{(8,10,13,15)}$, whereas the reference method in the majority of studies that showed higher validity were food records ${ }^{(7,12,14,16)}$. Other validation studies used erythrocytes $^{(37-40)}$, adipose tissue ${ }^{(41)}$ or plasma ${ }^{(11,38,39)}$ as their reference method. Such biomarkers are considered to be a better reference for $n-3$ PUFA than 24HDR and food records, because of their uncorrelated errors to the FFQ. The observed validity in these biomarker studies ranged from fair ${ }^{(40-42)}$ to excellent ${ }^{(39)}$. In general, the validity was higher for FFQ that were specifically developed to measure $n$-3 PUFA intake ${ }^{(37-39)}$ than for FFQ that were similar to the EPIC-NL FFQ, developed with the aim to measure the total diet ${ }^{(40-42)}$. This illustrates another potential explanation for the lower validity in our study. In the EPIC-NL FFQ, intakes of fish products, the main food sources of EPA and DHA, were not asked separately but aggregated into three items, which could have led to an underestimation of intake ${ }^{(43)}$. Correspondingly, a previous validation study of the FFQ used in the present study ${ }^{(2)}$ showed similar fair validity for intake of fish $(r 0.32$ in men, $r 0.37$ in women).

In contrast to the underestimation of EPA and DHA, LA intake was overestimated by the FFQ as compared with the 24HDR in our study population. This overestimation increased with higher intake levels, and may be caused by the additional and detailed questions about added fats and margarines in the questionnaire, which are an important source of LA in the population.

The validity of an FFQ is specific to the FFQ and to the study population it is administered to. In general, validation studies show obvious differences in validity across FFQ and also across all types of fatty acids. There is no indication that one particular fatty acid is commonly better captured by FFQ as compared with another fatty acid. This implies that we cannot generalise the validity of one FFQ to another, but each FFQ needs to be validated separately for its ability to measure fatty acids.

To conclude, the FFQ used in EPIC-NL showed moderate to good reproducibility for the assessment of intakes of specific fatty acid classes and individual fatty acids. Furthermore, for the fatty acids that are highly abundant in the Dutch diet, this FFQ is an adequate tool to rank people according to their intakes. Relative validity was less for intakes of low-abundant fatty acids including short-chain SFA, AA and marine $n-3$ PUFA.

\section{Acknowledgements}

The EPIC-NL study was funded by 'Europe against Cancer' Programme of the European Commission; the Dutch Ministry of Health, Welfare and Sports; The Netherlands Organization for Health Research and Development; and the World Cancer Research Fund.

The authors contributions to this manuscript were as follows: J. W. J. B. and Y. T. v. d. S. designed the study; J. P. and A. P. J. A. conducted the research and analysed the data; J. P., A. P. J. A.,
I. S., Y. T. v. d. S. and J. W. J. B. interpreted the data; J. P. and A. P. J. A. drafted the paper; C. T. M. v. R., I. S. and Y. T. v. d. S. and J. B. critically revised the paper for intellectual content and provided final approval of the manuscript.

J. P. is financially supported by a restricted research grant from Unilever Research and Development, Vlaardingen, The Netherlands. The other authors report no conflicts of interest.

\section{Supplementary material}

For supplementary material/s referred to in this article, please visit http://dx.doi.org/doi:10.1017/S000711451600132X

\section{References}

1. Beulens JW, Monninkhof EM, Verschuren WM, et al. (2010) Cohort profile: the EPIC-NL study. Int J Epidemiol 39, 1170-1178.

2. Ocke MC, Bueno-de-Mesquita HB, Goddijn HE, et al. (1997) The Dutch EPIC food frequency questionnaire. I. Description of the questionnaire, and relative validity and reproducibility for food groups. Int J Epidemiol 26, Suppl. 1, S37-S48.

3. Ocke MC, Bueno-de-Mesquita HB, Pols MA, et al. (1997) The Dutch EPIC food frequency questionnaire. II. Relative validity and reproducibility for nutrients. Int J Epidemiol 26, Suppl. 1, S49-S58.

4. Skeaff CM \& Miller J (2009) Dietary fat and coronary heart disease: summary of evidence from prospective cohort and randomised controlled trials. Ann Nutr Metab 55, 173-201.

5. Hu FB, Stampfer MJ, Manson JE, et al. (1999) Dietary saturated fats and their food sources in relation to the risk of coronary heart disease in women. Am J Clin Nutr 70, 1001-1008.

6. Mensink RP, Zock PL, Kester AD, et al. (2003) Effects of dietary fatty acids and carbohydrates on the ratio of serum total to HDL cholesterol and on serum lipids and apolipoproteins: a meta-analysis of 60 controlled trials. Am J Clin Nutr 77, 1146-1155.

7. Broadfield E, McKeever T, Fogarty A, et al. (2003) Measuring dietary fatty acid intake: validation of a food-frequency questionnaire against $7 \mathrm{~d}$ weighed records. Br J Nutr 90, $215-220$

8. Jaceldo-Siegl K, Knutsen SF, Sabate J, et al. (2010) Validation of nutrient intake using an FFQ and repeated $24 \mathrm{~h}$ recalls in black and white subjects of the Adventist Health Study-2 (AHS-2). Public Health Nutr 13, 812-819.

9. Kabagambe EK, Baylin A, Allan DA, et al. (2001) Application of the method of triads to evaluate the performance of food frequency questionnaires and biomarkers as indicators of long-term dietary intake. Am J Epidemiol 154, 1126-1135.

10. Lora KR, Lewis NM, Eskridge KM, et al. (2010) Validity and reliability of an omega-3 fatty acid food frequency questionnaire for first-generation Midwestern Latinas. Nutr Res 30 , 550-557.

11. McNaughton SA, Hughes MC \& Marks GC (2007) Validation of a FFQ to estimate the intake of PUFA using plasma phospholipid fatty acids and weighed foods records. Br J Nutr 97, 561-568.

12. Riboli E, Elmstahl S, Saracci R, et al. (1997) The Malmo Food Study: validity of two dietary assessment methods for measuring nutrient intake. Int J Epidemiol 26, Suppl. 1, S161-S173.

13. Segovia-Siapco G, Singh P, Jaceldo-Siegl K, et al. (2007) Validation of a food-frequency questionnaire for measurement of nutrient intake in a dietary intervention study. Public Health Nutr 10, 177-184. 
14. Sullivan BL, Brown J, Williams PG, et al. (2008) Dietary validation of a new Australian food-frequency questionnaire that estimates long-chain $n-3$ polyunsaturated fatty acids. $B r J$ Nutr 99, 660-666.

15. Wennberg M, Vessby B \& Johansson I (2009) Evaluation of relative intake of fatty acids according to the Northern Sweden FFQ with fatty acid levels in erythrocyte membranes as biomarkers. Public Health Nutr 12, 1477-1484.

16. Wolk A, Ljung H, Vessby B, et al. (1998) Effect of additional questions about fat on the validity of fat estimates from a food frequency questionnaire. Study Group of MRS SWEA. Eur J Clin Nutr 52, 186-192.

17. Cantwell MM, Gibney MJ, Cronin D, et al. (2005) Development and validation of a food-frequency questionnaire for the determination of detailed fatty acid intakes. Public Health Nutr 8, 97-107.

18. Willett WC, Howe GR \& Kushi LH (1997) Adjustment for total energy intake in epidemiologic studies. Am J Clin Nutr 65 , 1220S-1228S; discussion 1229S-1231S.

19 Willett W (1998) Nutritional Epidemiology. New York and Oxford: Oxford University Press.

20. Arab L (2003) Biomarkers of fat and fatty acid intake. J Nutr 133, Suppl. 3, 925S-932S.

21. Riboli E (1992) Nutrition and cancer: background and rationale of the European Prospective Investigation into Cancer and Nutrition (EPIC). Ann Oncol 3, 783-791.

22. Saadatian-Elahi M, Slimani N, Chajes V, et al. (2009) Plasma phospholipid fatty acid profiles and their association with food intakes: results from a cross-sectional study within the European Prospective Investigation into Cancer and Nutrition. Am J Clin Nutr 89, 331-346.

23. Collins CE, Boggess MM, Watson JF, et al. (2014) Reproducibility and comparative validity of a food frequency questionnaire for Australian adults. Clin Nutr 33, 906-914.

24. Hernandez-Avila M, Romieu I, Parra S, et al. (1998) Validity and reproducibility of a food frequency questionnaire to assess dietary intake of women living in Mexico City. Salud Publica Mex 40, 133-140.

25. Horn-Ross PL, Lee VS, Collins CN, et al. (2008) Dietary assessment in the California Teachers Study: reproducibility and validity. Cancer Causes Control 19, 595-603.

26. Laviolle B, Froger-Bompas C, Guillo P, et al. (2005) Relative validity and reproducibility of a 14-item semi-quantitative food frequency questionnaire for cardiovascular prevention. Eur J Cardiovasc Prev Rehabil 12, 587-595.

27. Filippi AR, Amodio E, Napoli G, et al. (2014) The web-based ASSO-food frequency questionnaire for adolescents: relative and absolute reproducibility assessment. Nutr J 13, 119.

28. Lafay L, Mennen L, Basdevant A, et al. (2000) Does energy intake underreporting involve all kinds of food or only specific food items? Results from the Fleurbaix Laventie Ville Sante (FLVS) study. Int J Obes Relat Metab Disord 24, 1500-1506.
29. Johnson RK, Goran MI \& Poehlman ET (1994) Correlates of over- and underreporting of energy intake in healthy older men and women. Am J Clin Nutr 59, 1286-1290.

30. Krebs-Smith SM, Graubard BI, Kahle LL, et al. (2000) Low energy reporters vs others: a comparison of reported food intakes. Eur J Clin Nutr 54, 281-287.

31. Livingstone MB \& Black AE (2003) Markers of the validity of reported energy intake. J Nutr 133, Suppl. 3, 895S-920S.

32. Ferrari P, Slimani N, Ciampi A, et al. (2002) Evaluation of under- and overreporting of energy intake in the 24-hour diet recalls in the European Prospective Investigation into Cancer and Nutrition (EPIC). Public Health Nutr 5, 1329-1345.

33. Heitmann BL (1993) The influence of fatness, weight change, slimming history and other lifestyle variables on diet reporting in Danish men and women aged 35-65 years. Int J Obes Relat Metab Disord 17, 329-336.

34. Lafay L, Basdevant A, Charles MA, et al. (1997) Determinants and nature of dietary underreporting in a free-living population: the Fleurbaix Laventie Ville Sante (FLVS) Study. Int J Obes Relat Metab Disord 21, 567-573.

35. Tooze JA, Subar AF, Thompson FE, et al. (2004) Psychosocial predictors of energy underreporting in a large doubly labeled water study. Am J Clin Nutr 79, 795-804.

36. Subar AF, Thompson FE, Kipnis V, et al. (2001) Comparative validation of the Block, Willett, and National Cancer Institute food frequency questionnaires: the Eating at America's Table Study. Am J Epidemiol 154, 1089-1099.

37. Ingram MA, Stonehouse W, Russell KG, et al. (2012) The New Zealand PUFA semiquantitative food frequency questionnaire is a valid and reliable tool to assess PUFA intakes in healthy New Zealand adults. J Nutr 142, 1968-1974.

38. Sullivan BL, Williams PG \& Meyer BJ (2006) Biomarker validation of a long-chain omega-3 polyunsaturated fatty acid food frequency questionnaire. Lipids 41, 845-850.

39. Swierk M, Williams PG, Wilcox J, et al. (2011) Validation of an Australian electronic food frequency questionnaire to measure polyunsaturated fatty acid intake. Nutrition 27, 641-646.

40. Zhang B, Wang P, Chen CG, et al. (2010) Validation of an FFQ to estimate the intake of fatty acids using erythrocyte membrane fatty acids and multiple $3 \mathrm{~d}$ dietary records. Public Health Nutr 13, 1546-1552.

41. Wallin A, Di Giuseppe D, Burgaz A, et al. (2014) Validity of food frequency questionnaire-based estimates of long-term long-chain $n-3$ polyunsaturated fatty acid intake. Eur J Nutr 53, 549-555

42. Lepsch J, Vaz JS, Moreira JD, et al. (2015) Food frequency questionnaire as an indicator of the serum composition of essential $n-3$ and $n-6$ polyunsaturated fatty acids in early pregnancy, according to body mass index. J Hum Nutr Diet 28, 85-94.

43. Serdula M, Byers T, Coates R, et al. (1992) Assessing consumption of high-fat foods: the effect of grouping foods into single questions. Epidemiology 3, 503-508. 